\title{
Factor Price Equalisation and Trade Patterns with Unemployment
}

\author{
Paul Oslington \\ University of Oxford and Deakin University
}

\begin{abstract}
This paper extends the technique of integrated equilibrium analysis to con sider a trading world with unemployment due to a wage floor. Unlike previous models with wage floors, world goods prices and patterns of production are endogenous. This more general analysis of a trading world allows questions of the effect of unemployment on the likelihood of factor price equalisation and the factor content of trade to be addressed. Results are relevant to the recent debates over trade and wage inequality/ unemployment, to empirical tests of factor proportions theories of trade, and to the international harmonisation of labour standards. (JEL Classifications: F11, F16) \&ey Words: Integrated equilibrium, Unemployment, $\mathrm{M}$ inimum wage.>
\end{abstract}

\section{Introduction}

Despite significant unemployment in major trading economies, and intense popular debate, unemployment issues have not been prominent in economists

\footnotetext{
* Correspondence Address: Department of Economics, University of Oxford, M anor Rd, Oxford, OX1 3UL, UK and School of Economics, Deakin University, Geelong 3217, Australia. (E-mail) osling@deakin.edu.au. I thank Jeff Sheen, Alan Woodland, Bill Schworm, Avinash Dixit and D onald Davis for helpful comments on the paper.
}

(C2000 - Center for International Economics, Sejong Institution. All rights reserved. 
discussions of trade theory and policy. There are models in the literature of single trading economies subject to unemployment in the literature (Haberler [1950], Brecher [1974], Neary [1985] among others) but some fundamental questions about a global economy where there is unemployment have not yet been considered. This paper extends the technique of integrated equilibrium analysis (Dixit and Norman [1980], Helpman and Krugman [1985], Davis [1998]) to consider a number of questions about an integrated global economy with unemployment. It adopts what Davis [1998; p478-479] calls a "truly global approach", where goods prices and the patterns specialisation are endogenous, linked to underlying technology, tastes, endowments and the factor market distortion.

A fundamental question is conditions for and likelihood of factor price equalisation with unemployment. As is pointed out by Deardorff [1994; p167168] it is an inescapable question for trade economists because factor price equalisation assumptions are built into most theoretical and empirical work on trade. The likelihood of factor price equalisation is of considerable interest in itself, but is also crucial understanding the much debated wage inequality/ unemployment changes in the OECD and elsewhere. Davis' recent paper [1998] particularly stresses the importance of modelling an integrated global economy for s a progress on this issue.

Another fundamental question is the effect of unemployment on patterns of specialisation and trade in a global economy. This question is also of considerable interest - for instance if we can better understand how unemployment modifies trade flows, this should improve the performance of the HeckscherOhlin type models in empirical tests. If the factor market distortion in this paper is interpreted as an international labour standard the results contribute to our understanding of the effects of such as standard.

The paper is organised as follows. Section II begins with a brief description of integrated equilibrium analysis, and then section III extends it to an economy with unemployment due to a factor market distortion - a binding wage floor. Section IV considers the likelihood of factor price equalisation while section $\mathrm{V}$ deals with the pattern and volume of trade, illustrating a case where a wage floor reverses the trade pattern that would be predicted by the countries' relative factor endowments. Section VI discusses the problem of multiple equilibria created by the unemployment and suggests some resolutions 
which yield additional results. Section VII concludes and reviews the relevance to a number of current issues.

\section{Integrated Equilibrium Analysis}

The analytical technique used in the paper is integrated equilibrium analysis which was first hinted at by Samuelson [1949], then elaborated by Travis [1964], Dixit and Norman [1980], Helpman and Krugman [1985]. It builds on the canonical general equilibrium trade model which assumes competition, concave constant returns to scale technology that is the same across the world, and identical homothetic preferences. For simplicity of exposition there will be two countries, each with two factors of production and two goods ${ }^{1}$. It will be assumed that equilibrium factor proportions are unique and degenerate combinations of technology, endowments and tastes which mean a good is produced nowhere in the world will be ruled out. It will also be assumed that there is some substitutability in both production and consumption.

Before introducing the minimum wage, the integrated equilibrium technique will be briefly explained for the benefit of the readers unfamiliar with it. Consider an integrated world where there is free movement of both goods and factors. World endowments, technology and preferences jointly determine an equilibrium factor price vector denoted $w$, equilibrium factor proportions for the goods denoted $a^{1}(w)$ to produce a unit of good 1 (which uses factor 1 relatively intensively) and $a^{2}(w)$ to produce a unit of good 2 , and outputs of the goods $y^{1}$ and $y^{2}$. Goods prices are also determined. This equilibrium for an integrated world is illustrated in figure 1 , which shows the factor usage vectors $y^{1} a^{1}(w)$ and $y^{2} a^{2}(w)$ (which are the product of the output of a good and its unit factor usage vector) drawn in a factor quantity space box, the dimensions of which are the world endowments of the factors, denoted $v^{1}$ and $v^{2}$ with origin 0 . Consumption equals production for the world, so the end point diagonal of the box, which coincides with the sum of the factor usage

1. Generalisation to higher numbers of goods and factors is straightforward as the analysis does not rely on pairings of factors and goods, as noted by Dixit and Norman [1980]. 
Figure 1

\section{Integrated Equilibrium}

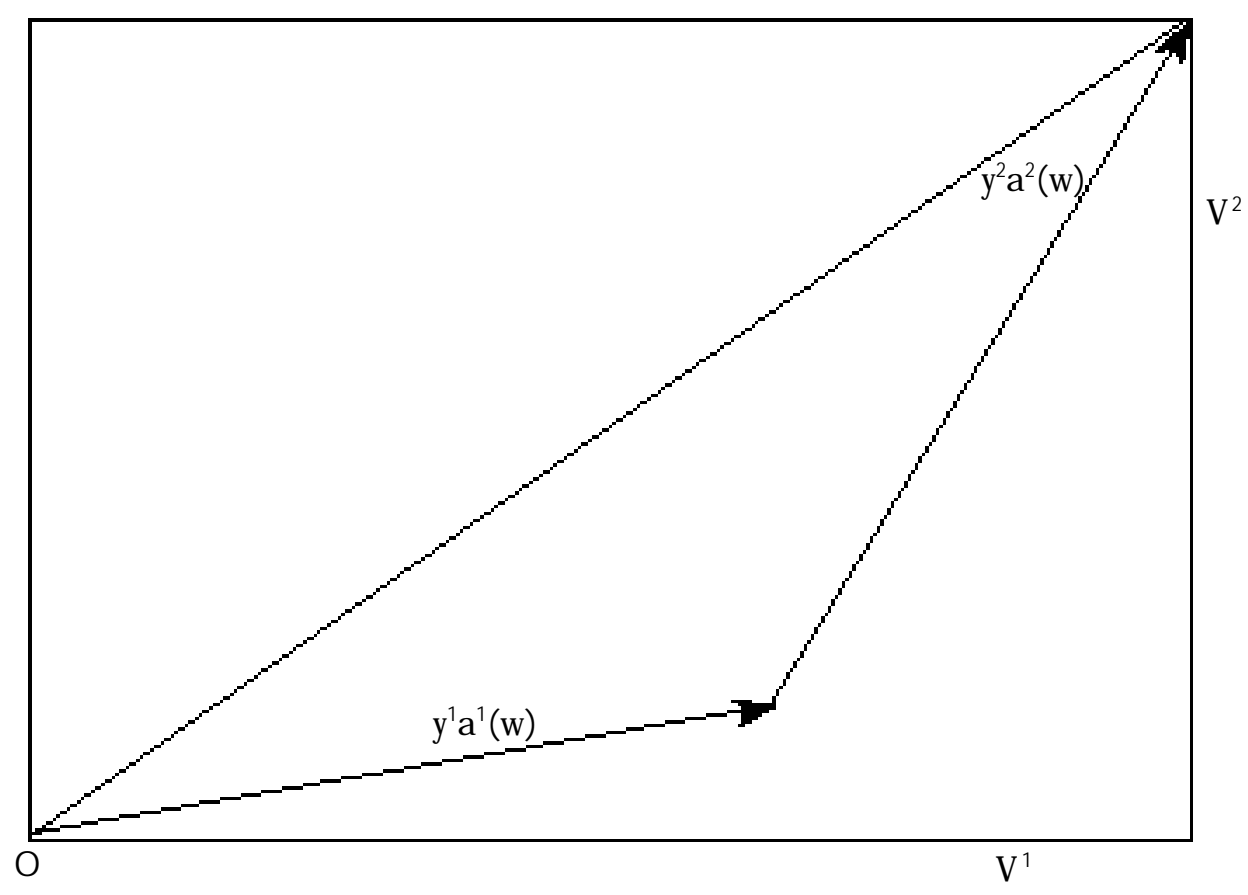

vectors, is the factor content of consumption.

Now consider dividing this integrated world into countries, each receiving part of the world endowment of factors, ruling out movement of factors between countries, although goods can still move freely. In figure 2 a division of the endowment is represented by $E$ with the origin for the home endowment $O$ and foreign $O^{*}$. $E$ is above the diagonal of the box, indicating that the home country is relatively well endowed with factor 2 . This division of the endowment allows both countries to produce both goods using the integrated equilibrium factor proportions and the factor usage vectors are $y^{1} a^{1}(w), y^{2}$ $a^{2}(w)$ for home and $y^{1^{*}} a^{1}(w), y^{2^{*}} a^{2}(w)$ for foreign. These vectors are drawn from their respective origins and meet at $E$, indicating that there is full employment. The Samuelson result of equal factor prices in each country holds. The factor content of consumption in each country will be the same as the integrated equilibrium because preferences are identical homothetic, so consumption points for the countries will lie on the diagonal of the box. To 
Figure 2

\section{Divided Equilibrium}

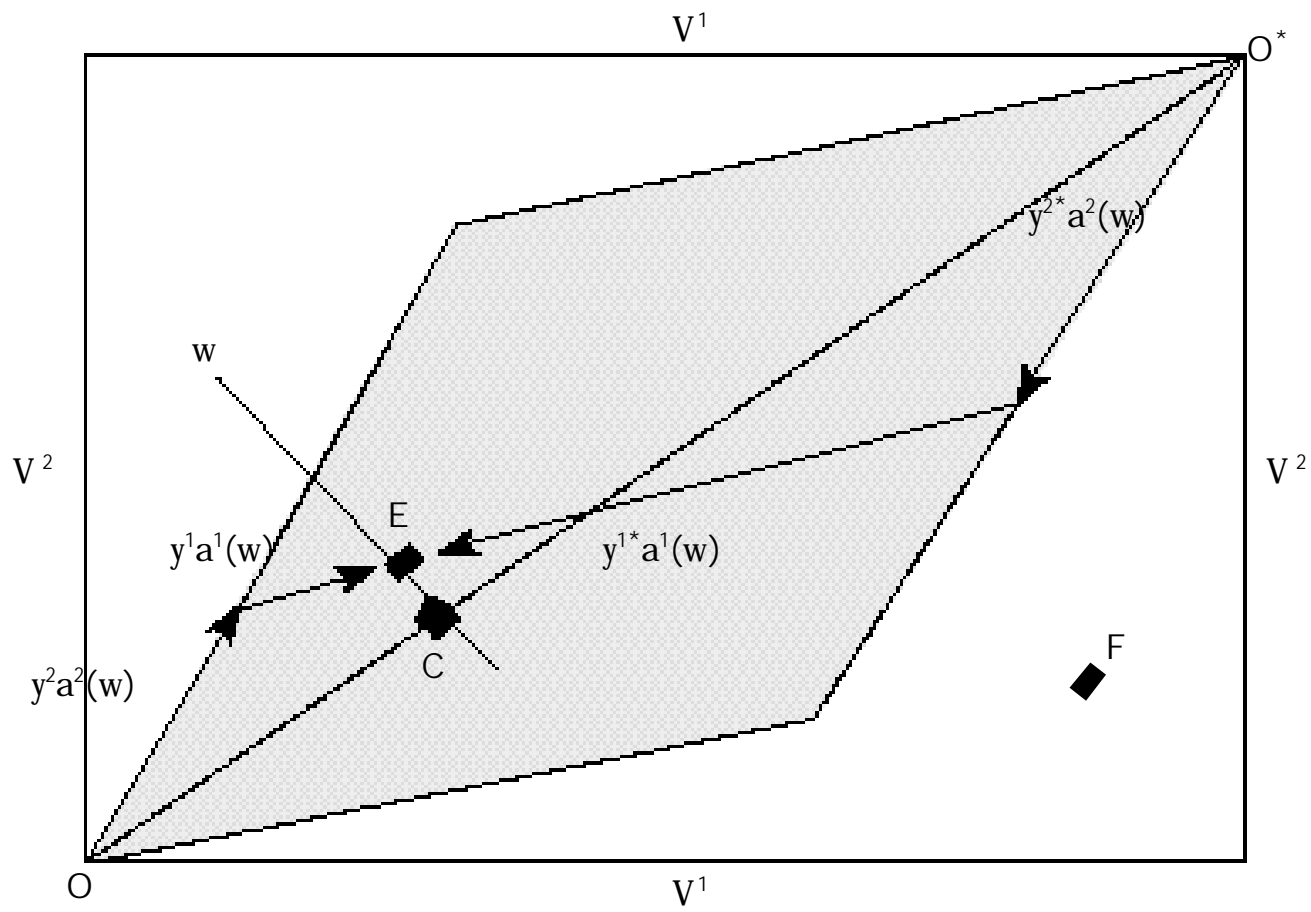

identify the consumption points for each country a line with slope w representing factor prices can be drawn through the endowment point $E$, with a slope defined by the dimensions of the box. The consumption point $C$ is then the intersection of this factor price line and the diagonal of the box. The factor content of trade is thus EC, and we see the Heckscher-Ohlin-Vanek result holds - that the home country, being relatively well endowed with factor 2 implicitly exports that factor and implicitly impor ts the other factor.

Drawing goods consumption vectors on figure 2 and subtracting these from the goods output vectors would yield net export of goods vectors and verify the Heckscher-Ohlin theorem - the home country exports good 2 which uses its relatively abundant factor 2 relatively intensively. In the subsequent analysis the emphasis will be on the Heckscher-Ohlin-Vanek result about the factor content of trade, because the Heckscher-Ohlin theorem about goods trade is problematic when there are more than two goods, and because integrated equilibrium technique puts factor quantities and prices in 
the for eground leaving goods quantities and prices in the background.

A similar replication of the integrated equilibrium will be possible for all points like $E$ in figure 2 that lie within the shaded parallelogram formed by the integrated equilibrium factor usage vectors drawn from both origins. For allocations of the world endowment like $F$ outside the parallelogram replication of the integrated equilibrium is not possible, one or both of the countries will cease producing one of the goods, goods will not be produced using the integrated equilibrium factor proportions, and factor prices will not be equalised ${ }^{2}$.

\section{Integrated Equilibrium Analysis with Unemployment}

A global economy with unemployment due to a binding wage floor will now be considered. This wage floor might arise from government minimum wage or labour standard law, the existence of government unemployment and welfare benefits, or some kind of efficiency wage effect ${ }^{3}$.

Integrated equilibrium analysis is a powerful technique, but the logic of comparing otherwise identical integrated and divided economies makes it best suited to considering a wage floor that is common to all countries. In fact, the likelihood of factor price equalisation can only be meaningfully considered under these conditions. The reason is that specifying different minimum wages in different parts of the world ties down the division of the world factor endowment between the countries, precluding the investigation of different divisions of the world endowment which is the essence of integrated equilibrium analysis. Later in the paper when considering the pattern of trade the wage floor can either be interpreted as common to all countries, or else existing in just one country provided that the conditions for factor price equalisation are met $^{4}$.

So as to be able to consider the fundamental factor price equalisation issue,

2. F urther details of what happens outside the set, discussions of the size of the set, as well as extensions to more goods and factors, nontraded goods and imperfect competition may be found in Travis [1964; pp7-67], Dixit and Norman [1980; pp110-125], Helpman and Krugman [1985; pp12-29] and Deardorff [1994].

3. A possible extension would be to endogenise the minimum wage, depending on union bargaining as in Kemp, Long and Shimomura [1991], efficiency wage effects as in M atusz [1996], or insider-outsider effects as in Oslington [1998; ch7]. 
the interpretation of the floor as common to all countries will be used. This interpretation also makes the results relevant to world where there are political pressures to harmonise labour standards. Efficiency wage effects could reasonably be expected to be similar across countries with identical technology, but it is acknowledged that union bargained wages would probably not be the same in countries with different factor proportions.

The other features to note about the wage floor are that it applies to a single factor in all industries, and is defined as a ratio of the price of the factor to the other factor ${ }^{5}$.

A minimum wage $\hat{w}$ which raises the price of factor 2 relative to the price of factor 1 will affect the integrated equilibrium factor proportions so that firms in both industries will use a lower proportion of factor 2 to factor 1 . The new proportions, shown in figure 3 by $a^{1}(\hat{w})$ and $a^{2}(\hat{w})$ are flatter than those without the minimum wage (drawn fine dotted for comparison, carried over from figure 1). If both factors were to be fully employed with these new factor proportions the integrated equilibrium is factor usage vectors would be $\tilde{y}^{1} a^{1}(\hat{w})$ and $\tilde{y}^{2} a^{2}(\hat{w})$ which are the thick dashed lines in figure 3 , but these are inconsistent with equilibrium since they involve both a smaller output and a lower relative price of good 1 . There is an excess relative demand for good 1 , and equilibrium requires resources to shift away from good 2 to good 1 . This shift reduces the usage of factor 2 in industry 2 by more than the increase in the usage of factor 2 in industry 1 , because of the relative factor intensities of the goods, leaving some factor 2 unemployed. The new outputs and factor usage vectors consistent with equilibrium in figure 3 are thus

4. Davis [1998] took the later route and used integrated equilibrium techniques with a minimum wage in just one country, plus an assumption that factor price equalisation holds. This decision, while helpful for his question of interactions between European and American factor markets, meant that he could not consider the likelihood of factor price equalisation.

5. Krugman [1995] defines the minimum wage as a ratio of factor prices, while Brecher[1974] defines it with reference to goods prices. The present analysis is consistent with either definition, provided the minimum wage lowers the equilibrium labour intensity in both industries. Brecher [1974] and Krugman [1995] set the minimum wage at the level of the value of marginal product of labour in autarky, so there is no unemployment in autarky. This is unnecessarily restrictive, although it simplifies their analyses. 
Figure 3

\section{Integrated Equilibrium with Unemployment}

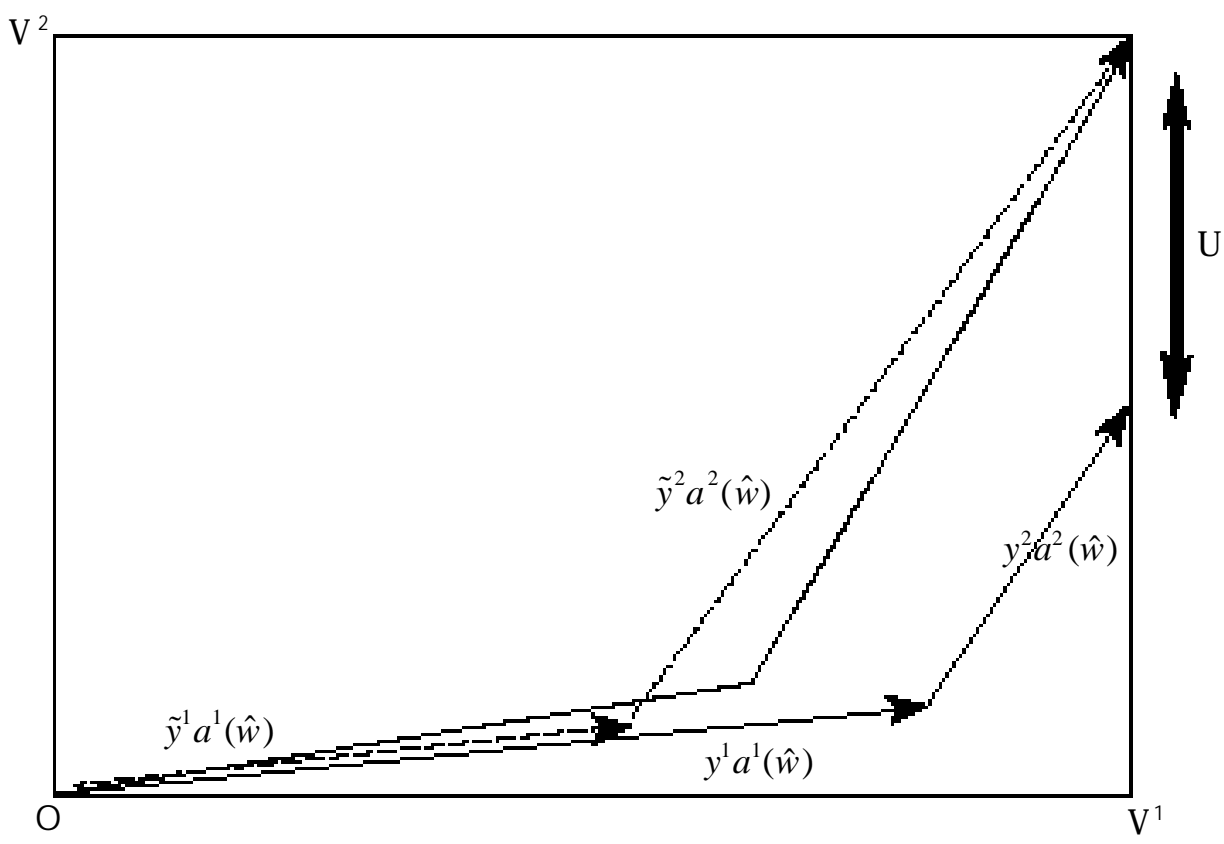

$y^{1} a^{1}(\hat{w})$ and $y^{2} a^{2}(\hat{w})$ and unemployment is marked $\mathrm{U}$. Overall the minimum wage lowers the factor 2 intensity of both industries, reallocates factor 1 from industry 2 to industry 1 , causes unemployment of factor 2 , has an uncertain effect on output of good 1 and reduces the output of good 2 .

Considering a division of this integrated equilibrium into countries is more complex when there is unemployment. The origins from which the factor usage vectors are drawn must be adjusted to reflect unemployment in the countries. In figure 4, for an endowment split $E$, a divided equilibrium which replicates the integrated equilibrium is represented by the factor usage vectors $y^{\prime 1} a^{1}(\hat{w}), y^{\prime 2} a^{2}(\hat{w})$ for home and $y^{1^{*}} a^{1}(\hat{w}), y^{2^{*}} a^{2}(\hat{w})$ for foreign. These vectors are drawn from the home and foreign origins, adjusted for the distribution of unemployment $U^{\prime}$ and $U^{*}$ ' between the countries implied by these factor usage vectors. Factor usage vectors which replicate the integrated equilibrium can be formed in the same way for other divisions of the endowment that lie between the upper and lower arms marked in figure 4 (these arms are the integrated equilibrium factor usage vectors drawn from the home and foreign ori- 
Figure 4

Divided Equilibrium with Unemployment

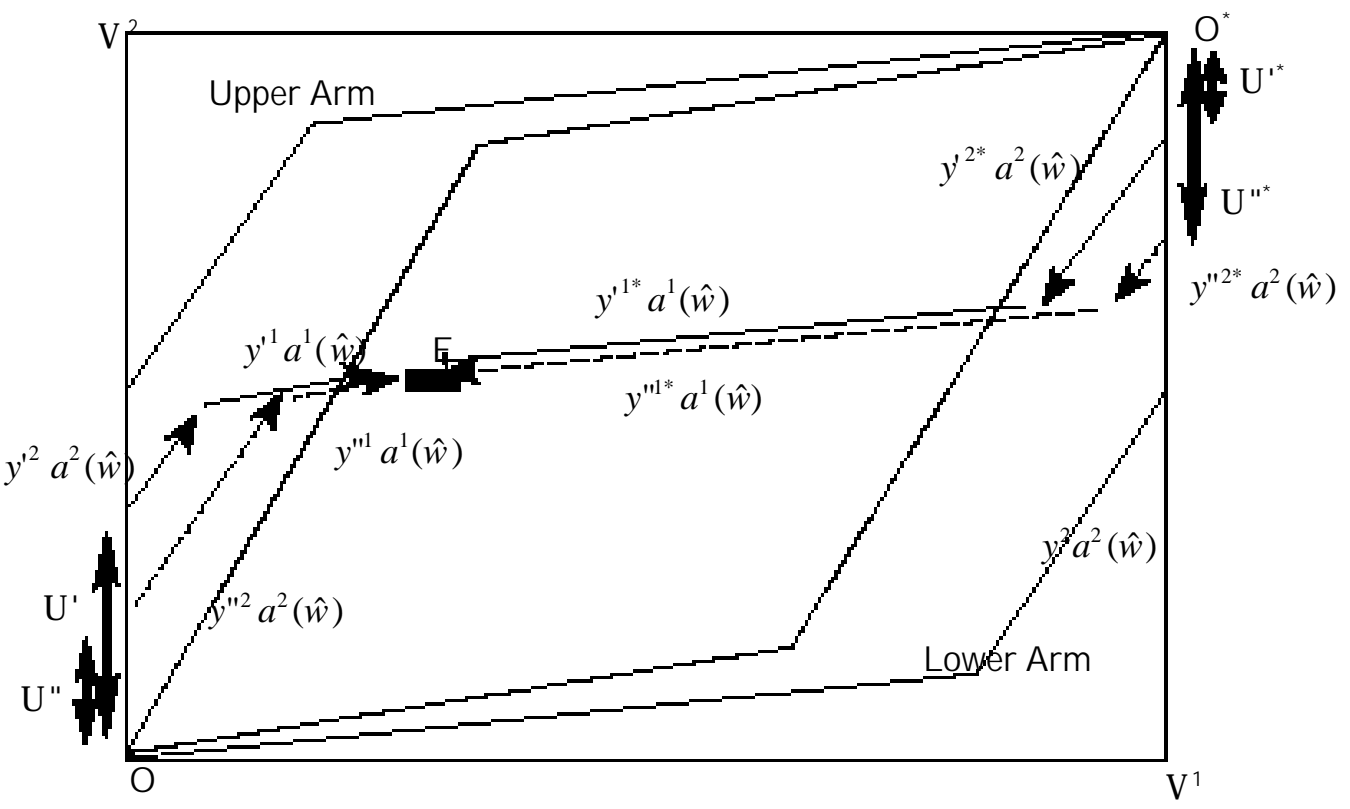

gins- the same as $y^{1} a^{1}(\hat{w})$ and $y^{2} a^{2}(\hat{w})$ from figure 3$)$. If the endowment split is not within the arms, diversification and replication of the integrated equilibrium is not possible, so one of the countries will specialise completely in one of the goods in a manner analogous to the model without the minimum wage.

Restricting attention to divisions within the arms which allow replication of the integrated equilibrium, it should be noted that there are other possible equilibrium factor usage vectors and thus unemployment distributions for $\mathrm{E}$ apart from $y^{\prime 1} a^{1}(\hat{w}) \quad y^{\prime 2} a^{2}(\hat{w})$ and $U^{\prime} U^{\prime *}$ - for instance $y^{\prime \prime 1} a^{1}(\hat{w}) y^{\prime \prime 2} a^{2}(\hat{w})$ $y^{\prime \prime 1} a^{1}(\hat{w}) \quad y^{\prime \prime 2} a^{2}(\hat{w})$ and $U^{\prime \prime} U^{\prime \prime *}$ in figure 4- which also replicate the integrated equilibrium. These alternative vectors represent the same world output and unemployment but the distribution of output and unemployment between the countries is different. A worldwide minimum wage thus introduces an arbitrary element into output and unemployment levels for a particular country, although world outputs and employment are uniquely determined. Factor content of consumption ratios for both countries are the same as in the integrated equilibrium but the distribution of consumption depends on the distri- 
bution of output and unemployment between the countries. Additional assumptions which eliminate this range of indeterminacy will be considered in a section VI, but some results about the effect of a minimum wage on factor price equalisation and the pattern of trade can be derived irrespective of the indeterminacy, and these will be considered in sections IV and V.

\section{Factor Price Equalisation with Unemployment}

The debate over factor price equalisation under full employment has been extensive. Samuelson [1949, 1953, 1967], McKenzie [1955] and others have derived sufficient conditions for factor price equalisation under full employment with given goods prices, which are: no factor intensity reversals, identical technology across the world, and all goods produced in all countries. These papers took world goods prices as given, as was standard until Dixit and Norman [1980] considered factor price equalisation with endogenous prices, using integrated equilibrium analysis.

Dixit and Norman [1980] showed that there will be factor price equalisation when the integrated equilibrium is replicated, so the set of endowment divisions within the shaded region in figure 5 (based on figures 2 and 4) like $E$ which allow replication for a given combinations of world prices, technology and endowments is a factor price equalisation set. Points like $F$ outside the set do not allow replication of the integrated equilibrium and factor prices will not be equalised.

The likelihood of factor price equalisation was defined by Dixit and Norman [1980] and Helpman and Krugman [1985] in the following way. If equal probability is assigned to all divisions of the endowment then likelihood of factor price equalisation is the probability that a randomly drawn endowment division will exhibit factor price equalisation. This means that the likelihood is the proportion of the box within the factor price equalisation set.

An obvious question is whether anything can be said about the effect of a wage floor on the size of the factor price equalisation set and thus the likelihood of factor price equalisation, along the lines of Deardorff and Courant's [1986] finding that adding a nontraded good reduces the likelihood of factor price equalisation.

The minimum wage factor price equalisation set - which is the shaded area 


\section{Figure 5}

\section{Factor Price Equalisation Set with Unemployment}

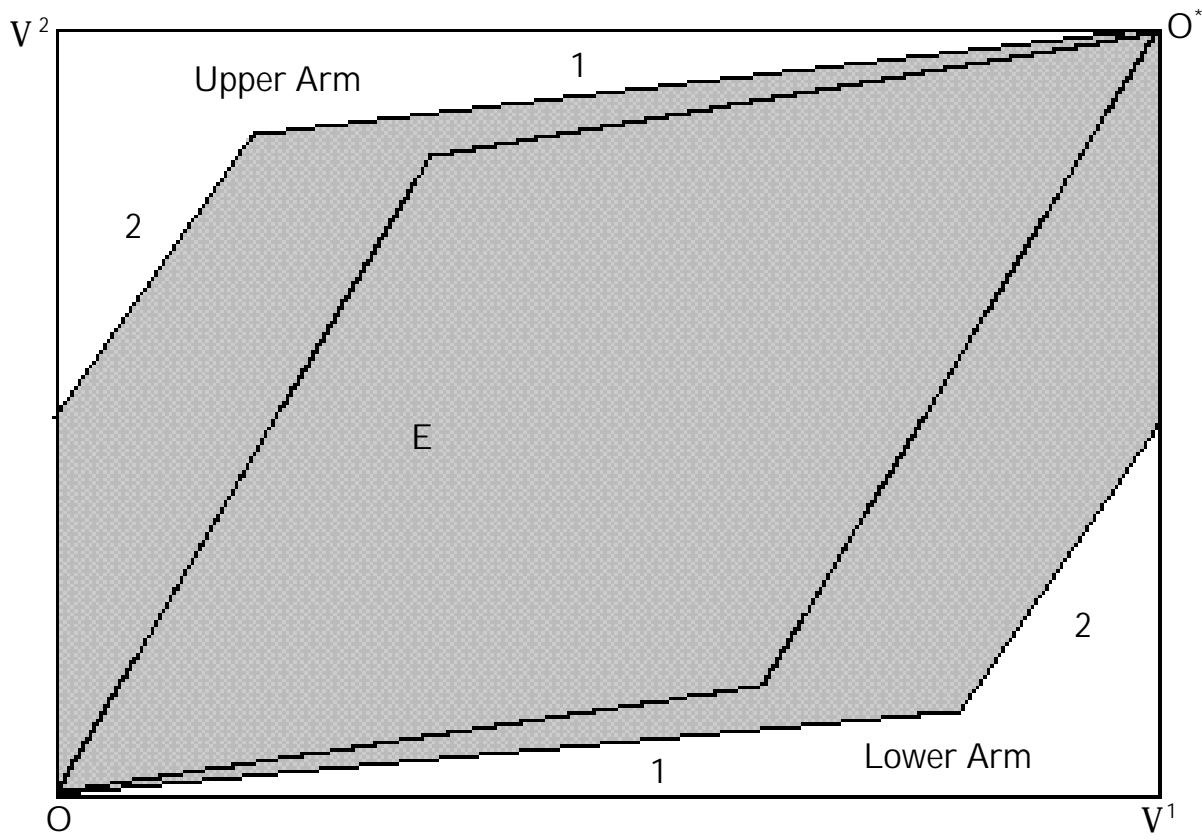

between the upper and lower arms in figure 5 - is clearly larger than the full employment factor price equalisation set - which is the dotted parallelogram. Will this be so in general?

Theorem 1: Under the assumptions of the analysis, the likelihood of factor price equalisation is increased by the imposition of a minimum wage which causes unemployment.

Proof: From the discussion of the integrated equilibrium with unemployment in section III a minimum wage means both industries become less factor 2 intensive and some factor 1 is drawn out of industry 2 into industry 1 . In terms of figure 5 this means that the industry 1 component of the lower arm will always be flatter and longer than the corresponding component of the full employment parallelogram. Since the industry 2 component of the lower arm is also flatter the corresponding component of the parallelogram, the minimum wage lower arm will always lie outside the parallelogram. Repeating the 
argument for the upper arm completes the argument that the arms which define the minimum wage factor price equalisation set will always enclose the parallelogram which defines the full employment factor price equalisation set, for all possible technologies and binding minimum wages.?

It might be thought that this result is an unsurprising consequence of the reduction in the number of flexible price factors relative to the number of goods. Dixit and Norman [1980; pp119-121] however show that adding goods (which has an equivalent effect on dimensionality as subtracting factors) need not increase the size of the factor price equalisation set. Ethier's [1984] analysis stresses the requirement for factor price equalisation that the number of international markets be at least as great as the number of factors, but there is no presumption that fur ther increases in the number of markets relative to the number of factors will increase the likelihood of factor price equalisation. The literature thus does not indicate there is any presumption that reducing the number of flexible price factors relative to the number of goods will increase the likelihood of factor price equalisation. Theorem 1 is not an artefact of the change in dimensionality ${ }^{6}$.

\section{Pattern and Volume of Trade with Unemployment}

The Heckscher-Ohlin-Vanek theorem predicts that a country will implicitly export its relatively abundant factor, but does this hold with unemployment?

Theorem 2: Under the assumptions of the analysis there exist endowment divi sions which support a mi nimum wage unemployment equilibrium with an oppo site pattern of trade to that predicted by the Heckscher-O hlin-Vanek theorem based on underlying endowments.

Proof: Consider the endowment division $\mathrm{E}$ in figure 6. A possible set of factor usage vectors and associated distribution of unemployment between the countries is shown for $\mathrm{E}$, which are the previously discussed $y^{\prime 1} a^{1}(\hat{w}) y^{\prime 2} a^{2}(\hat{w})$

6. One of the advantages of considering minimum wages in a fully specified model of a trading world is that artificial dimensionality effects like the impossibility of diversification in a two factor two good small open economy with a minimum wage discovered by Brecher [1974] do not arise. 
Figure 6

Trade Pattern Reversal with Unemployment

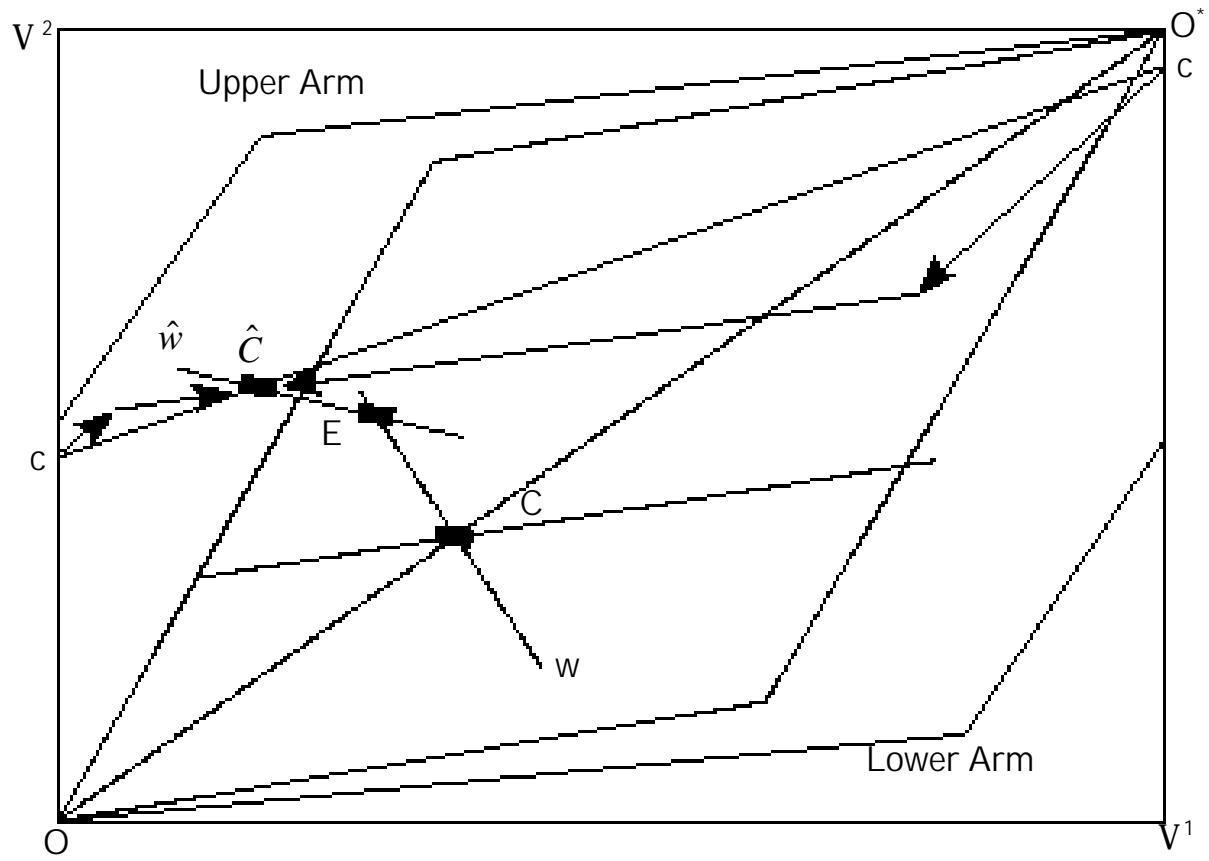

$y^{\prime 1^{*}} a^{1}(\hat{w}) \quad y^{2^{*}} a^{2}(\hat{w})$ and $U^{\prime} U^{*} *$ from figure 4. To determine the factor content of trade we have to consider consumption, and the fact that consumer expenditure equals factor income ties the consumption point down to some point on the diagonal cc drawn between the origins of the factor usage vectors. This consumption diagonal with unemployment is flatter than the diagonal of the box because the minimum wage reduces the relative factor 2 content of world production and factor content of world consumption equals production. Another way of looking at it is that the minimum wage raises the relative world price of good 2, reducing the relative demand for good 2. Drawing a line through $\mathrm{E}$ with slope $\hat{w}$ representing the factor prices to cut the diagonal cc gives consumption point $\hat{C}$, so with unemployment the home country implicitly exports factor 1 and imports factor 2. Comparing this to the full employment situation for the same endowment split $\mathrm{E}$, where the factor content of consumption was $C$, and the home country implicitly exported its rela- 
tively abundant factor 2 and implicitly imported factor 1 , the trade pattern has been reversed by the minimum wage.

A reversal of the trade pattern is an extreme case, and even when it does not occur the minimum wage tends to reduce the minimum wage factor content of net exports of the country relatively well endowed with the minimum wage factor.

The intuition behind these results is that unemployment caused by the minimum wage masks the relative endowment effect, altering the comparative advantages of the countries. It might be objected that trade is still consistent with the Heckscher-Ohlin-Vanek theorem if reinterpreted in terms of ex post factor usages, although such theorems based on ex post magnitudes are of limited use (see for example the argument of Woodland [1982]). The objection thus has limited force.

\section{Resolving the Multiple Equilibria}

In section 3 it was shown that for a given endowment division there are multiple distributions of the integrated equilibrium output, unemployment and consumption between the countries, although the total world output, unemployment and consumption is determined. This arbitrariness can be resolved by making an additional assumption which ties down the distribution of unemployment between the countries. It could for instance be assumed that all the unemployment occurs in the home country, or that the unemployment is distributed in proportion to the countries' endowments of the unemployed factor, but these assumptions lack an adequate economic basis.

An assumption which has a stronger basis is that there are infinitesimally small transport cost attached to moving goods across national boundaries ${ }^{7}$. The consequence of this assumption is that where the price system allows multiple equilibria, the equilibrium which involves the least trade will be selected, and this equilibrium will imply certain factor usage vectors and a split of unemployment and consumption between the countries. This can mean that a minimum wage wipes out trade between countries that would

7. This is the assumption as implicit in the standard trade theoretic statement that there is no trade if countries have the same autarky goods prices. 
other wise have traded gainfully with each other.

Theorem 3: Under the assumptions of the analysis, including the existence of infinitesimally small international transport costs for goods, there exist endow ment divisions for which a minimum wage eliminates trade between countries which would otherwise have traded ${ }^{8}$.

Proof: Consider the endowment division $\mathrm{E}$ in figure 7. Without the small transport costs there were many possible output, unemployment and consumption distributions including those shown in figure 6, which implied trade. With the transport costs the unique trade minimising output vectors, unemployment distribution and consumption diagonal marked dd will be selected. Since the diagonal passes through $E$ the factor content of consumption point $\hat{D}$ coincides with the endowment point $E$ and there is no trade, contrasting with the trading equilibria illustrated in figure 6.

For other endowment splits like $\mathrm{H}$ in figure 7, where the trade minimising consumption diagonal is $\mathrm{Oa}$, trade is not completely wiped out when there is unemployment, the consumption point being $\hat{A}$ and trade being $\mathrm{H} \hat{A}$.

The point of the modified analysis with small transport costs to resolve the indeterminacy is to highlight the trade destroying effects of unemployment. Trade is destroyed because the excess demands created by differences between the countries are resolved by changes in the distribution of unemployment between the countries, rather than being resolved by trade as in the full employment case.

\section{Conclusions}

This paper has extended the technique of integrated equilibrium analysis to consider a number of fundamental questions about trade in the presence of a wage floor. This has allowed the question of factor price equalisation with unemployment to be addressed for the first time, and has indicated how trade flows are determined in terms of the underlying technology, endowments and

8. The resolution of the indeterminacy with small transport costs does not affect Theorem 1. It does weaken Theorem 2 so that a wiping out of trade rather than a reversal of the trade pattern is the extreme case of the unemployment effect. 
Figure 7

\section{Equilibria with Small Transport Costs}

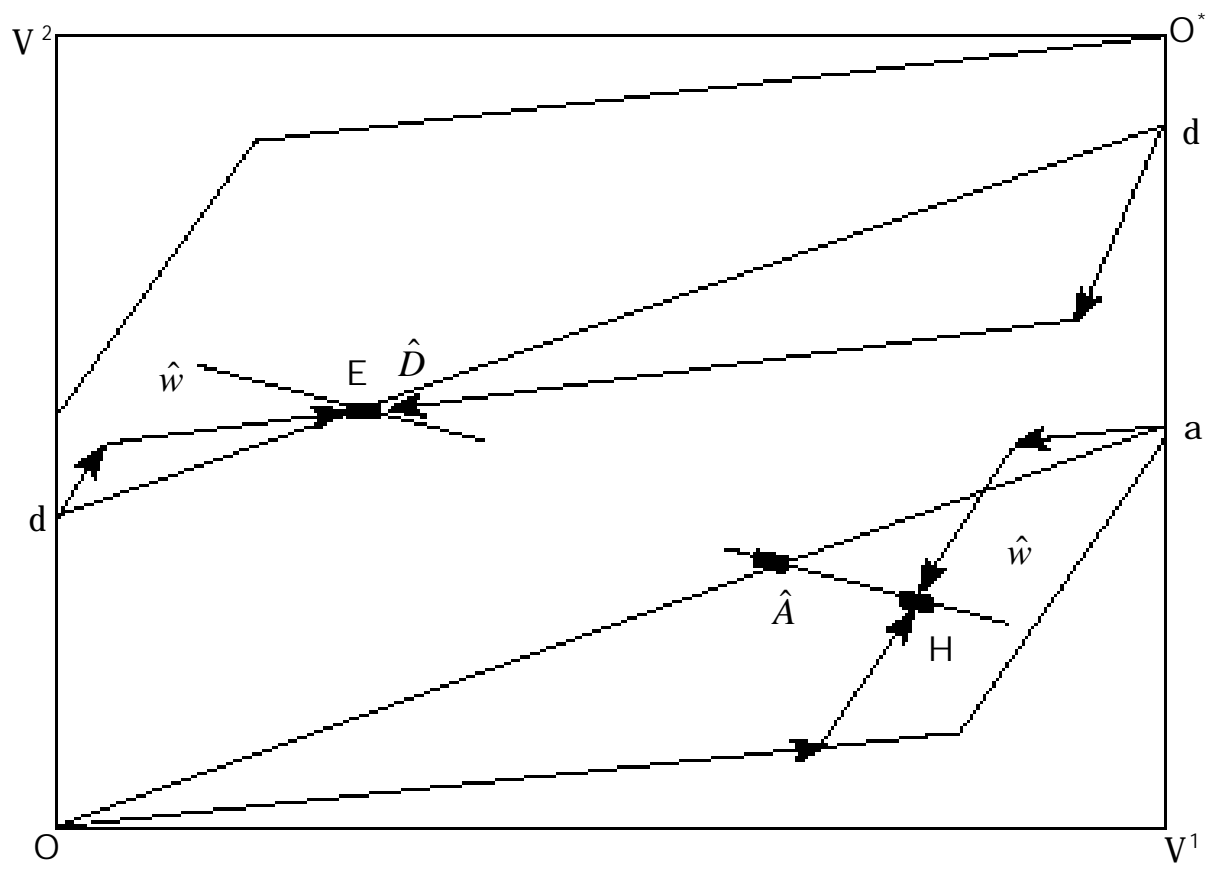

minimum wages. It was shown that existing patterns of comparative advantage could be nullified by unemployment, giving a reversal the trade pattern that would have otherwise existed, and in other circumstances wiping out gainful trade. The indeterminacy result reinforces this, suggesting another reason why trade predicted by endowment theories is not observed, or observed to a lesser extent in a world with unemployment.

As was suggested in the introduction a better understanding of relationships between unemployment, factor prices and trade is of considerable theoretical interest, as well as being relevant to a number of contemporary issues.

Firstly, there was the issue of the relationship between trade and the rising inequality and unemployment across the OECD. Krugman [1995] and Davis [1998] have begun to use integrated equilibrium tools in relation to this issue, under the restrictive assumption that factor price equalisation holds. The current paper looks at the question at a more fundamental level by investigating the likelihood of factor price equalisation, providing a foundation for further 
work along these lines. Analysis which takes seriously the point that trade, wages and unemployment are determined simultaneously with reference to the underlying characteristics of the global economy seems crucial to progress on this issue.

Secondly, there is the issue of the empirical performance of the factor proportions explanation of trade flows, and the much debated Leontieff paradox. If minimum wage unemployment alters trade patterns and volumes, and there is significant unemployment in the countries for which the tests are being conducted, tests based on endowments will be misleading unless modified to take account of unemployment. We saw that countries with large endowments of factors subject to a wage floor will have lower net exports of these than would be predicted by the standard model, so modifying the empirical models to take account of this should improve their empirical performance.

Thirdly, the results are relevant to debates over the effects of the international harmonisation of labour standards on trade, factor prices and the distribution of unemployment across countries. The indeterminacy of unemployment, and trade destroying effects of a harmonised labour standard do not seem to have been previously recognised.

\section{References}

B recher, Richard A. [1974], "M inimum Wage Rates and the Pure Theory of International Trade," Quarterly Journal of E conomics 88; pp. 98-116.

Deardorff, Alan V. and Paul N. Courant [1990], "On the Likelihood of F actor Price Equalisation with Nontraded Goods," International Economic Review 31(3); pp. 589-596.

Deardorff, Alan V. [1994], "The Possibility of Factor Price Equalisation Revisited," Journal of I nternational E conomics 36; pp. 167-175.

Davis, Donald R. [1998], “D oes European Unemployment Prop up American Wages?" American E conomic Review 88(3); pp. 478-494.

Dixit, Avinash K. and Victor Norman [1980], The Theory of International Trade - A Dual General Equilibrium Approach, Cambridge: Cambridge University Press .

Ethier, Wilfred J. [1984], "Higher Dimensional Issues in Trade Theory" in Jones Ronald W. and Kenen Peter B., (eds.) The Handbook of Interna - 
tional Economics, Vol, 1 Amsterdam: N or th H olland.

Haberler, Gottfried [1950], "Some Problems in the Pure Theory of International Trade," E conomic Journal 60; pp. 223-240.

Helpman, Elhanan and Paul R. Krugman [1985], Market Structure and For eign Trade, M assachusetts:M IT Press.

Johnson, Harry G. [1969], "M inimum Wage Laws: A General Equilibrium Analysis," Canadian Journal of Economics 2(4); pp. 599-604.

Kemp, M urray C., Ngo Van Long and Koji Shimomura [1991], Labour Unions and the Theory of International Trade, Amsterdam: N or th Holland .

Krugman, Paul P. [1995], "Growing World Trade: Causes and Consequences,"

B rookings Papers on Economic Activity 1; pp. 327-377.

M atusz, Stephen [1996], "International Trade, the Division of Labour and Unemployment," International E conomic Review 37(1); pp. 71-84.

M cK enzie L. [1955], "E quality of Factor Prices in World Trade," Econometrica 23(3); pp. 239-257.

Neary, J. Peter [1985], "International Factor M obility, M inimum Wage Rates, and Factor Price Equalisation: A Synthesis," Quarterly Journal of Eco nomics 100(3); pp. 551-570.

Oslington, Paul [1998], Unemployment in an Open Economy, PhD Thesis, University of Sydney.

Samuelson, Paul A. [1949],"International Factor Price Equalisation Once Again," E conomic Journal 59; pp. 181-197.

Samuelson, Paul A. [1953], "Prices of Goods and Factors in General Equilibrium," Revi ew of E conomic Studies 21; pp. 1-20.

Samuelson, Paul A. [1967], "Summary on Factor Price Equalisation," Intema tional Economic Review 8; pp. 286-295.

Travis, William P. [1985], The Theory of Trade and Protection, M assachusetts: $\mathrm{H}$ anvard University Press.

Woodland Alan D. [1982], International Trade and Resource Allocation, Amsterdam:N orth Holland. 